\title{
A FEM based methodology to simulate multiple crack propagation in friction stir welds
}

\author{
Lepore, Marcello; Carlone, Pierpaolo ; Berto, Filippo; Sonne, Mads Rostgaard
}

Published in:

Engineering Fracture Mechanics

Link to article, DOI:

10.1016/j.engfracmech.2017.08.024

Publication date:

2017

Document Version

Peer reviewed version

Link back to DTU Orbit

Citation (APA):

Lepore, M., Carlone, P., Berto, F., \& Sonne, M. R. (2017). A FEM based methodology to simulate multiple crack propagation in friction stir welds. Engineering Fracture Mechanics, 154-167.

https://doi.org/10.1016/j.engfracmech.2017.08.024

\section{General rights}

Copyright and moral rights for the publications made accessible in the public portal are retained by the authors and/or other copyright owners and it is a condition of accessing publications that users recognise and abide by the legal requirements associated with these rights.

- Users may download and print one copy of any publication from the public portal for the purpose of private study or research.

- You may not further distribute the material or use it for any profit-making activity or commercial gain

- You may freely distribute the URL identifying the publication in the public portal

If you believe that this document breaches copyright please contact us providing details, and we will remove access to the work immediately and investigate your claim 


\section{Accepted Manuscript}

A FEM based methodology to simulate multiple crack propagation in friction stir welds

Marcello Lepore, Pierpaolo Carlone, Filippo Berto, Mads R. Sonne

PII: S0013-7944(17)30653-7

DOI: http://dx.doi.org/10.1016/j.engfracmech.2017.08.024

Reference: EFM 5658

To appear in:

$$
\text { Engineering Fracture Mechanics }
$$

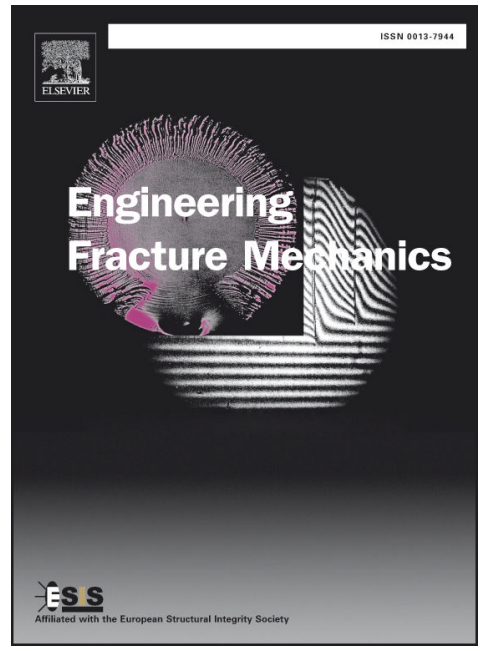

Received Date: $\quad 28$ June 2017

Revised Date: $\quad 12$ August 2017

Accepted Date: 13 August 2017

Please cite this article as: Lepore, M., Carlone, P., Berto, F., Sonne, M.R., A FEM based methodology to simulate multiple crack propagation in friction stir welds, Engineering Fracture Mechanics (2017), doi: http://dx.doi.org/ 10.1016/j.engfracmech.2017.08.024

This is a PDF file of an unedited manuscript that has been accepted for publication. As a service to our customers we are providing this early version of the manuscript. The manuscript will undergo copyediting, typesetting, and review of the resulting proof before it is published in its final form. Please note that during the production process errors may be discovered which could affect the content, and all legal disclaimers that apply to the journal pertain. 


\title{
A FEM based methodology to simulate multiple crack propagation in friction stir welds
}

\author{
Marcello Lepore ${ }^{\mathrm{a}}$, Pierpaolo Carlone ${ }^{\mathrm{a}}$, Filippo Berto ${ }^{\mathrm{b}}$, Mads R. Sonne ${ }^{\mathrm{c}}$ \\ ${ }^{a}$ Department of Industrial Engineering, University of Salerno, Via G. Paolo II 132, 84084 Fisciano (SA), Italy \\ ${ }^{b}$ Department of Mechanical and Industrial Engineering, NTNU, Richard Birkelands vei 2b, 7491 Trondheim, Norway \\ ${ }^{c}$ Department of Mechanical Engineering, Technical University of Denmark, 2800 Kgs. Lyngby, Denmark
}

\begin{abstract}
In this work a numerical procedure, based on a finite element approach, is proposed to simulate multiple three-dimensional crack propagation in a welded structure. Cracks are introduced in a friction stir welded AA2024-T3 butt joint, affected by a process-induced residual stress scenario. The residual stress field was inferred by a thermo-mechanical FEM simulation of the process, considering temperature dependent elastic-plastic material properties, material softening and isotropic hardening. Afterwards, cracks introduced in the selected location of FEM computational domain allow stress redistribution and fatigue crack growth. The proposed approach has been validated by comparison with numerical outcomes provided by a consolidated FEM-DBEM procedure, available in literature. The discussed procedures are substantially equivalent in terms of SIFs evaluation along the crack front at the cracks insertion, as well as with respect to crack sizes measured in three different points for each propagation step. This FEMbased approach simulates the fatigue crack propagation by considering accurately the residual stress field generated by plastic deformations imposed on a structural component and has general validity.
\end{abstract}

\section{Keywords: FSW, FEM, FEM-DBEM, Residual Stress, Crack growth}

\begin{tabular}{|c|c|}
\hline \multicolumn{2}{|c|}{ Nomenclature } \\
\hline FSW & friction stir welding \\
\hline FEM & finite element method \\
\hline DBEM & dual boundary element method \\
\hline FEM-DBEM & coupled finite and dual boundary element methods \\
\hline SIF & stress intensity factor \\
\hline KI, KII, KIII & mode I, II and III of stress intensity factors \\
\hline $\mathrm{K}_{\mathrm{C}}$ & fracture toughness \\
\hline $\mathrm{K}_{\mathrm{IC}}$ & mode I fracture toughness \\
\hline $3 \mathrm{D}$ & three-dimensional \\
\hline LEFM & linear elastic fracture mechanic \\
\hline MERR & maximum energy release rate \\
\hline VCE & virtual crack extension \\
\hline$\Delta \mathrm{K}$ & stress intensity factor range \\
\hline$\Delta \mathrm{K}_{\mathrm{th}}$ & threshold value of stress intensity factor range \\
\hline $\mathrm{K}_{\min }$ & minimum value of stress intensity factor \\
\hline $\mathrm{K}_{\max }$ & maximum value of stress intensity factor \\
\hline $\mathrm{K}_{\text {max,th }}$ & $\mathrm{K}_{\max }$ fatigue threshold \\
\hline$A, \mathrm{n}, \mathrm{m}$ & Vasudevan's law parameters \\
\hline $\mathrm{J}_{1}, \mathrm{~J}_{2}, \mathrm{~J}_{3}$ & mode I, II and III of J integral \\
\hline B & term to set plain stress or plain strain \\
\hline$\alpha$ & measure of stress triaxiality degree \\
\hline$v$ & Poisson's ratio \\
\hline$\rho$ & material density \\
\hline$\sigma_{\text {yield }}$ & temperature dependent yield stress \\
\hline$c_{p}$ & specific heat \\
\hline $\mathrm{n}$ & number of tool revolutions per minute \\
\hline . & thermal conductivity \\
\hline $\mathrm{q}$ & surface heat flux \\
\hline$r$ & radial position originating from the tool center \\
\hline & temperature \\
\hline$\dot{Q}_{\text {gen }}^{\prime \prime \prime}$ & volumetric heat source term \\
\hline$\sigma_{\mathrm{ij}, \mathrm{j}}$ & components of stress tensor \\
\hline $\mathrm{p}_{\mathrm{j}}$ & components of volume forces \\
\hline $\mathrm{t}_{0}$ & plate thickness \\
\hline G & shear modulus \\
\hline $\mathrm{G}_{\mathrm{eq}}$ & equivalent energy release rate \\
\hline $\mathrm{G}_{\max , \mathrm{eq}}$ & maximum of equivalent energy release rate \\
\hline $\mathrm{A}, \mathrm{B}, \mathrm{C}$ & crack sizes \\
\hline
\end{tabular}




\section{Introduction}

Fatigue crack propagation in structural components has always been a challenging issues in several safety critical applications [1,2]. It is also well known that residual stresses, for instance induced at the manufacturing and welding stage, play a key role in crack growth rate [3,4]. Friction stir welding (FSW) is a relatively new solid state welding technology, whose application to aluminum structures is significantly increasing. Relevant benefits achievable by FSW process, with respect to conventional fusion welding, are related to the reduced porosity, distortion, and residual stresses. In recent years, several studies have been carried out to develop numerical tools capable of predicting the fatigue behavior of welded structures, as detailed in [5-14], to cite but a few.

In some cases the Boundary Element Method (BEM) is preferred, given the apparent simplification of re-meshing procedures, especially when dealing with mixed mode problems [15,16,17]. A BEM model, implemented for the simulation of crack propagation in FSW joints has been proposed and discussed by some of the present authors in [18,19]. In particular, the welding induced longitudinal residual stresses, obtained through an experimental measure in the cross section of the joint, were accounted for in the calculation. That is assumed to be an initial condition for the study of fatigue crack propagation. As obvious, the comprehensive definition of the residual stress tensor in all material locations is not practical and quite expensive, therefore, in several cases it is preferred to get them through numerical models. As far as FSW is regarded, established models for residual stress evaluation can be found in [20,21,22,23] such as that proposed by Hattel and colleagues [24]. Comprehensive review articles concerning FSW modelling and stress analysis are available in [25,26].

In this paper a purely FEM based procedure is proposed and tested to simulate the fatigue propagation of multiple three-dimensional cracks in a friction stir welded sample. An un-cracked FEM model is used to launch a thermo-mechanical welding simulation, in order to assess the process induced residual stress distribution. More precisely, two cracks were introduced at selected locations of the domain before the thermo-mechanical simulations, but enforcing virtual material continuity by the application of contact constraints, preventing penetration as well as mutual displacement of the crack faces. In this way the cracked FEM model is equivalent to an un-cracked one. Afterwards, such contact constraints were removed, allowing the residual stresses to redistribute, leading to a new equilibrium condition. Finally, a fatigue load is applied and the fatigue propagation of two cracks is simulated. To validate the proposed method, an analogue simulation of fatigue propagation is carried out in a DBEM environment, imposing the residual stresses (calculated in an un-cracked FEM model) as an initial condition and then applying the tensile load. The commercial codes ABAQUS and BEASY were used for the finite element and boundary element models, respectively.

\section{Materials and Methods}

In this section the developed approach is described. Basically, the procedure is constituted by three consecutive steps, aiming, respectively at the creation of the finite element model, the simulation of the welding process, i.e. the definition of the residual stress scenario, and finally the simulation of crack propagation. These steps are indicated, in what follows, as pre-setting, welding simulation, and crack propagation. In Figure 1, a flowchart of the computational tasks is depicted. Each step is commented in details below.

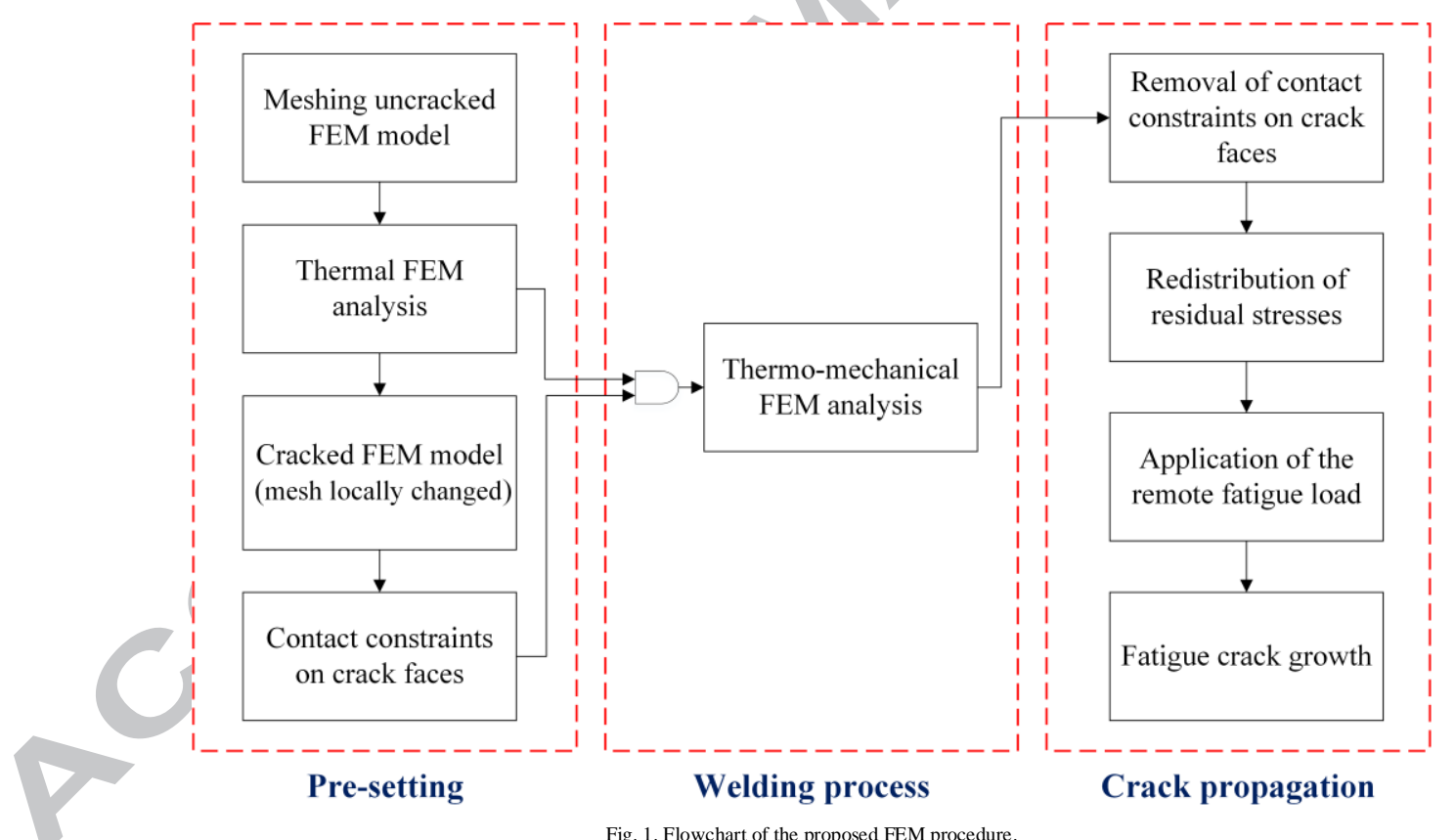

Fig. 1. Flowchart of the proposed FEM procedure.

\section{Pre-setting}

Firstly, the geometric model is meshed without modeling the cracks. Subsequently, a thermal analysis is performed in order to obtain a temperature distribution in the whole domain. Then, a commercial code (Zencrack), specific for Fracture Mechanics in FEM environment, interacts with Abaqus in order to introduce two cracks in the model changing locally the mesh. Then, contact constraints are imposed on the cracks faces in order to prevent their separation. Such constraints prevent interpenetration of crack faces as well as relative movements in normal and tangential directions. In particular, the crack nodes not belonging to the front line are not merged but only overlapping and have the same displacement and stress value. Therefore, this model with constrained crack faces is equivalent to the un-cracked one. Moreover, it is already prepared for the next cracks opening by simply removing those contact conditions.

\section{Welding process}

The friction stir welding process used as benchmark in the present study has been extensively studied by some of the present authors [27,28]. Two AA2024-T3 plates were joined in the butt configuration, according to the dimensions indicated in Figure 2 . A steel tool featuring a flat shoulder (20 
$\mathrm{mm}$ in diameter) and a smooth pin (larger diameter $6.2 \mathrm{~mm}$, angle of the cone $30^{\circ}$ and $3.8 \mathrm{~mm}$ height) is rotated at a speed of $1400 \mathrm{rpm}$, with a welding speed of $70 \mathrm{~mm} / \mathrm{min}$ and a tilt angle of $2^{\circ}$. The rotational and translational movement of the tool, along the welding path shown in Fig. 2, produces frictional heating of the underlying components and intimately remixes the base material, leading also to the formation of microstructurally different zones [29]. The chemical composition and the main mechanical characteristics of the considered alloy are well known and available in literature. The residual stresses distribution generated by the welding process is numerically evaluated by the thermo-mechanical model designed and validated by Hattel and coworkers in [30,31]. In this model, the two starting plates are considered as a single body, with uniform material properties throughout the domain. For the sake of completeness, the fundamentals of this model are herein reported. An exhaustive description of the thermomechanical model is available in [11].

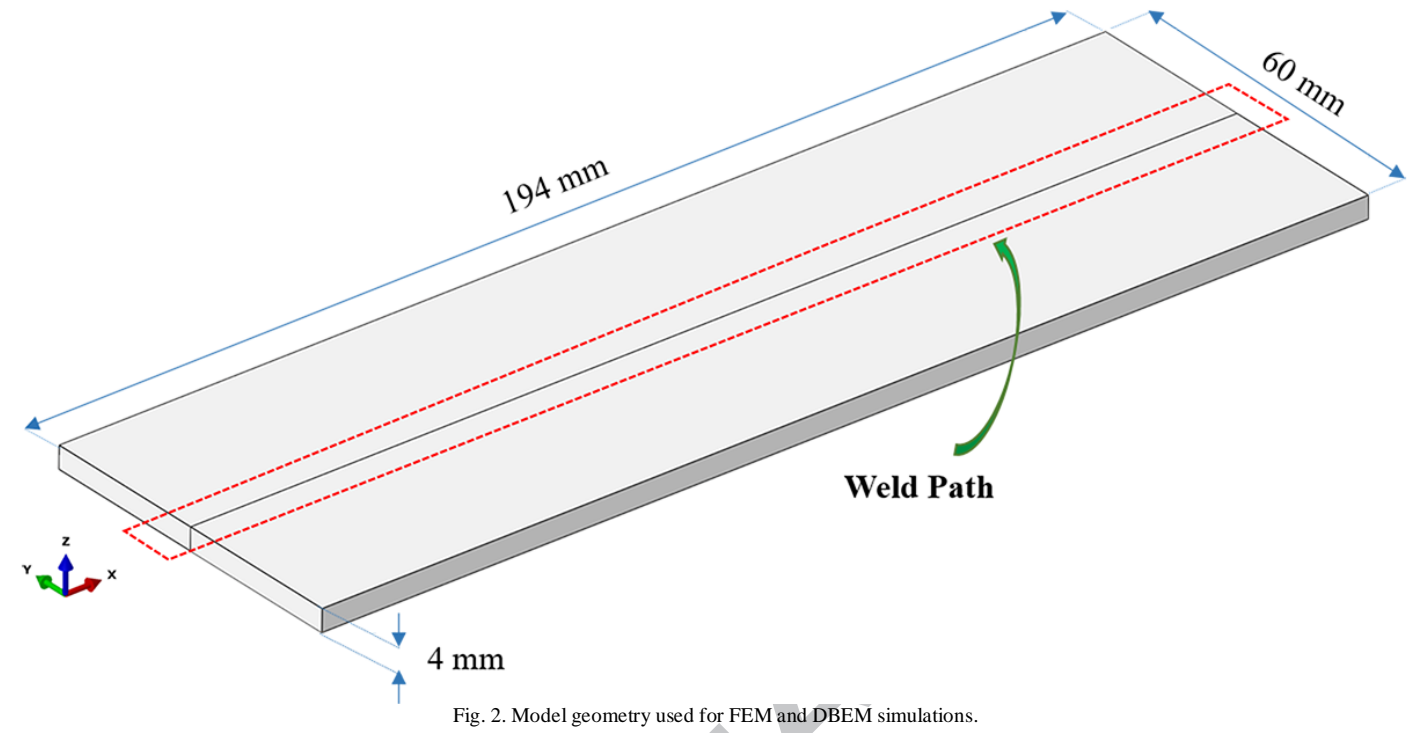

The model is based on assumption, commonly accepted, to overlook the material flow [22] because it reduces the computational complexity of simulation without penalizing the forecast accuracy. With that hypothesis, the thermo-mechanical problem is brought back to a Lagrangian form for which it is possible to calculate the whole problem solution in two distinct moments: thermal and mechanical. The two problems are solved sequentially, in particular, the latter after importing the transient temperature distribution inferred at the first step of the analysis. The time-dependent temperature distribution is obtained by solving the equation of transient heat conduction, which writes:

$\rho c_{p} \frac{\partial T}{\partial t}=\frac{\partial T}{\partial X}\left(k \frac{\partial T}{\partial X}\right)+\frac{\partial T}{\partial Y}\left(k \frac{\partial T}{\partial Y}\right)+\frac{\partial T}{\partial Z}\left(k \frac{\partial T}{\partial Z}\right)+\dot{Q}_{g e n}^{\prime \prime \prime}$

where $c_{\mathrm{p}}$ is the specific heat, $\mathrm{T}$ is the temperature, $\mathrm{k}$ is the thermal conductivity and $\dot{Q}_{\text {gen }}^{\prime \prime \prime}$ is the volumetric heat source term. The tool action is mimicked through an appropriate boundary condition that applies to the interface between the shoulder and the specimen. A radial and superficial heat flow q, depending on tool position and local yield stress (function of temperature), is imposed on contact area between the tool and the material without need to model the probe, as in the following:

$q(r, T)=\left(\frac{2 \pi n}{60}\right) r^{\sigma_{\text {yield }}} / \sqrt{3}$

where $\mathrm{q}$ is the surface heat flux, $\mathrm{n}$ is the number of tool revolutions per minute, is the radial position originating from the tool center and $\sigma_{\text {yield }}$ is the temperature dependent yield stress. In addition, this stress is regulated step by step to allow material softening attributable to microstructural changes. The yield stress is adjusted at each step so as to take into account the material softening, attributable to the microstructural changes, due essentially to the dissolution of the hardened precipitate caused by heating. For this purpose, it the Myhr and Grong model [32] is adopted, as already suggested in [13].

The equilibrium equation, solved at the mechanical iteration, is given by:

$\sigma_{i j, j}+p_{j}=0$

In equation (3) $\sigma_{\mathrm{ij}}$, $\mathrm{j}$ and $\mathrm{p}_{\mathrm{j}}$ indicate, respectively, the components of the stress tensor and the volume forces. The previously evaluated temperature distribution is used to calculate the thermal strain, applied as an internal load in the mechanical model. An implicit numerical scheme, based on the adoption of generalized Hooke law and a linear decomposition of strain tensor, are applied together with the expression of thermal deformation. Standard flow theory $\mathrm{J}_{2}$ with von Mises yielding surface, dependent on temperature and isotropic hardening, is used to evaluate the development of plastic strain [28]. ABAQUS commercial suite is used to implement and solve the thermo-mechanical model. A validation of the model with respect to temperature and stress calculation for the considered benchmark can be found in [23,24].

The simulation of thermo-mechanical problem consists in a sequence of five calculation steps. In the initial step (Initial), a uniform temperature of $25^{\circ} \mathrm{C}$ is introduced throughout the domain. In the second one (HeatIni), a heat source is generated and translating in the third step (HeatMove), along the welding path ( $\mathrm{X}$ axis of the global reference system), simulates the creation of the weld bead. In the fourth one (CoolDown), the joint cooling is achieved until the initial temperature is reached. In the fifth step (Releasing), the initial boundary conditions are removed and the new ones are introduced to eliminate only degrees of freedom of rigid body. At the end of the latter, the field of residual stresses is produced. The mesh of the uncracked model consists of 97624 eight-node linear elements (C3D8), corresponding to 113048 nodes, and the thickness is modeled with a row of six hexahedral elements. In addition, as the lateral is a through crack, each block positioned along direction of the front development and for each crack side, is replaced by a collapsed block taken from the standard S111 family. Instead, a collapsed block belonging to the standard S04 family is used for modeling the central crack. The standard block S111 contains a lot more number of elements than S04 and, thus, permits to evaluate the residual stresses more accurately having a greater mesh density. 


\section{Crack propagation}

The initial residual stress field is firstly evaluated and then the imposed constraints on the cracks faces are removed so that they are free to move and to open, redistributing the residual stresses, consequently. Particularly, such a redistribution involves the whole domain. This step is followed by imposition of a remote fatigue load, for the simulation of fatigue cracks propagation, guided by a suitable propagation law. It is overstating that the cracks propagation stops when the trough the tickness central crack reaches the boundary plate.

In environment DBEM, the residual stresses calculated in environment FEM for the un-cracked model are imported, transformed in Cauchy stresses and applied as tractions on each node of the crack faces elements. In more details, at each mesh point in the BEASY model the nearest FE element is located and the local coordinates are identified. Using an interpolation in the element, the FE stress results (displacement or stress) are computed. These results are then used to create the traction or displacement boundary condition at that location. The displacement is directly used as the boundary condition and the stress calculated at the point is converted to a traction using the normal surface.

The same model used for calculating residual stresses is used for the simulation of fatigue propagation. In this case, carts direct in three directions of the global reference system are applied, as boundary conditions, at one end of the joint while in the other it applies a uniform distribution of tractions direct along the $\mathrm{X}$ axis and equal to $100 \mathrm{MPa}$. Additionally, at the start of simulation, an initial temperature of $25^{\circ} \mathrm{C}$ is set to the whole domain in accordance with the previously model used for calculating residual stresses. In the model for fatigue propagation there are also constraints that prevent the joint bending along the $\mathrm{Z}$ axis. In fig. 3, J-paths are shown, arranged along the crack fronts and adequate for an accurate evaluation of SIFs profiles. The lateral crack is introduced in the FE model at $97 \mathrm{~mm}$ from the constrained surface while the central one is positioned at $77 \mathrm{~mm}$ from the same surface. In addition, the lateral crack is through the thickness and has a rectangular shape whose shorter side measures $2.5 \mathrm{~mm}$. The central, not through the thickness has a semi-elliptical shape and measures $1.9 \mathrm{~mm}$ for the lower semi-axis and 5.6mm for the larger one.

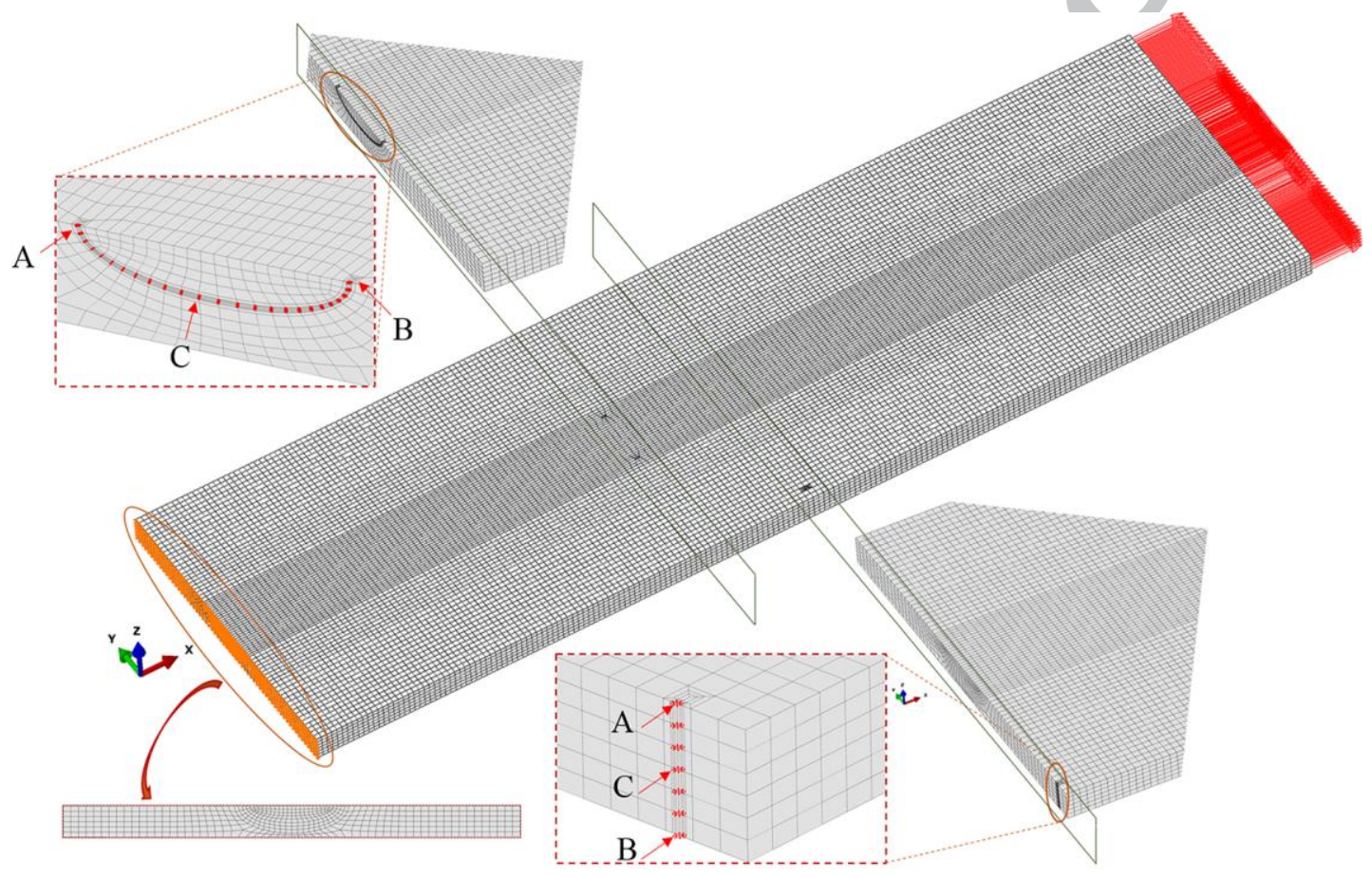

Fig. 2. Section planes of the FE model where the cracks are inserted with highlighting of J-Paths along the crack fronts.

In Fig. 3, the points A, B, C, positioned along the crack front and used for tracking the propagation paths are shown. Point $\mathrm{C}$ is positioned in the crack center, while points $\mathrm{A}$ and $\mathrm{B}$ correspond to the intersection of the crack with the free joint surface.

\section{Methods for calculating fracture parameters}

Zencrack, interacting with Abaqus, allows insertion of cracks with the simultaneous replacement of initial hexahedral elements, containing a part of the crack front, with collapsed elements; this implies an adaptation of the surrounding mesh that is produced through controlled and gradual deformations of neighboring elements. Through Zencrack, insertion of propagation law is also carried out as well as the crack growth and postprocessing of fracture parameters resulting from the calculation. It is important to note that cracks modeling is only possible if the mesh of the starting model (un-cracked) is made up of hexahedral elements [33]. Each crack is defined by a set of collapsed blocks that are distinguished in two groups: the first, consisting of collapsed facing elements, used for modeling the crack front and taken from a library where they are stored in families; the second, consisting of pairs of facing blocks, whose adjacent nodes are separated and used to model the crack faces. Each collapsed block is a set of $3 \mathrm{D}$ elements positioned inside a cube so as to contain each part of the crack front and, therefore, each face can be modeled with only one block or multiple adjacent blocks depending on the crack extension. In the crack blocks library, two macro families of collapsed blocks are distinguished: the first, containing "standard" blocks; the second, containing the "large" ones. FE simulations shown in this work use "standard" blocks.

Because of validity of Linear Elastic Fracture Mechanics (LEFM), the Energy Release Rate can be obtained by computing J-Integral, which in turn is directly usable to evaluate the Maximum Energy Release Rate (MERR). This is at basis of the selected criterion to define the direction of cracks fatigue propagation. Zencrack exploits the Virtual Crack Extension (VCE) technique, available in Abaqus, to generate multiple virtual crack extensions vectors. In cases with tridimensional defects, it is possible to define a normal plane tangent at front, in which up to seven vectors originate in the considered node of the front. The angles, defined by each vector with the plane of the crack to extend, differ between each other and determine a computing position for the G local. Subsequently, the maximum value is detected. Finally, the angle formed between the plane of the initial crack to extend and the vector at which the local G is maximum (MERR) becomes a propagation "direction" for that node.

This technique is repeated for each node of the crack face and, therefore, it allows to obtain an engineering and realistic front in which each node associates a kink angle. 
The predictive method used to extend the crack is the "forward predictor". At each front node, a maximum user-defined "da max" advancing crack increment is applied and introduced into the adopted propagation law. After integration of such law, dN values are obtained in each node of the front. Then, between these calculated values, the minimum dN value (dNlow) is detected and applied to all nodes of the crack front. Finally, a new integration is made for each node, assuming a constant ratio dG/da along the current crack increment (forward predictor), and the value of the current "da" is recalculated at each point of the front corresponding to a cycles number $\mathrm{dN}_{\text {low. }}$.

\section{Propagation law}

Abaqus uses the Contour method for calculating J-integral values, which are subsequently converted from Zencrack code into Stress Intensity Factors (SIF) and provided as inputs to the adopted propagation law.

The residual stresses affect the crack growth as they change the total value of the calculated SIF along the crack front, simultaneously acting on the minimum $\left(\mathrm{K}_{\min }\right)$ and maximum $\left(\mathrm{K}_{\max }\right) \mathrm{K}$, but leaving unaltered the $\Delta \mathrm{K}=\mathrm{K}_{\max }-\mathrm{K}_{\min }$. With the Vasudevan model it is considered that the main effect of the residual stresses on the crack growth rate is related to the variations of $\mathrm{K}_{\max }$ rather than those of $\Delta \mathrm{K}$. Considering a two-parameter model (Vasudevan), fatigue propagation of the crack is guided by two driving forces: $\Delta \mathrm{K}$ and $\mathrm{K}_{\max }$, so residual stresses can affect the growth rate even if they do not affect the $\Delta \mathrm{K}$. In addition, this theory considers two fatigue threshold values: $\mathrm{K}_{\max , \mathrm{th}}$ and $\Delta \mathrm{K}_{\mathrm{th}}$, corresponding to the two $\mathrm{K}_{\max }$ and $\Delta \mathrm{K}$ driving forces. Such forces must be greater than the threshold values because the fatigue crack propagates. Since residual stresses affect $K_{\max }$ levels, a propagation stop may occur if they are compressive and have a value such that $\mathrm{K}_{\max }$ is less than $\mathrm{K}_{\max , \mathrm{th}}$.

$d a / d N=A\left(\Delta K-\Delta K_{t h}\right)^{n}\left(K_{\max }-K_{\max , t h}\right)^{m}$

The parameters used in the formulation are available in literature and reported in Table 1 (for $\mathrm{R}=0.1$ ).

TABLE 1

\begin{tabular}{|l|l|l|l|l|}
\hline \multicolumn{5}{|c|}{ Propagation law parameters } \\
\hline$\Delta \mathrm{K}_{\mathrm{th}}$ & $\mathrm{K}_{\max , \mathrm{th}}$ & $A$ & $\mathrm{n}$ & $\mathrm{m}$ \\
\hline 1834121 & 3352014 & $6.745 \mathrm{E}-23$ & 1.65 & 0.56 \\
\hline
\end{tabular}

In addition to parameters reported in the table, $\mathrm{K}_{\mathrm{c}}$ has been computed, within the fatigue cracks propagation, for a minimum constraint condition with the following expression:

$K_{c}=\left(1+e^{-\left(t / t_{0}\right)}\right) K_{I c}=(1+0.97) 1008=1986 \operatorname{MPa} \sqrt{m m}=62.8 \mathrm{MPa} \sqrt{m}$

where, $\mathrm{t}_{0}=2.5\left(\mathrm{~K}_{\mathrm{Ic}} / \sigma_{\mathrm{y}}\right)^{4}=2.5(1008 / 331)^{4}=23.2 \mathrm{~mm}, \mathrm{t}=4 \mathrm{~mm}$ is the thickness of the plate and $\mathrm{e} \mathrm{K}_{\mathrm{Ic}}=1008 \mathrm{MPa}^{*} \mathrm{~mm}^{0.5}$ is the plane strain fracture toughness. These data are derived from the NASGRO database for Al2024-T3 Clad Plt; LA \& HHA. The latter is the material that best approximates that used in this work, while the yield stress is $\sigma_{y}=395 \mathrm{MPa}$, experimentally obtained.

The $\Delta K$ e $\mathrm{K}_{\max }$ used in the Vasudevan formula also consider, in addition to the KI, KII and KIII according to the formulas:

$\Delta K_{e q}=\Delta \sqrt{\overline{G_{e q}}}$

$K_{\max , e q}=\sqrt{G_{\max , e q}}$

then:

$G_{e q}=J_{1}+J_{2}+J_{3}=B / E\left(K_{I}^{2}+K_{I I}^{2}\right)+1 / 2 G K_{I I I}^{2}$

where $B=\left(1-v^{2}\right)$ for plain strain and $B=1$ for plain stress

whilst: $G_{\max , e q}=J_{1, \max }+J_{2, \max }+J_{3, \max }$

However, the KII and KIII values calculated along the crack fronts are negligible in this case, then the propagation is dominated by the only mode I.

It is important to note that the propagation law used in this work is written in terms of K. Zencrack calculates Energy Release Rate (G) and makes a conversion to $\mathrm{K}$ (K conversion) completely in automatic and for each one of calculation steps.

Alternatively, since propagation takes place in pure mode I, it is possible to rewrite the Vasudevan's proposed law in energys terms, considering instead of $\Delta \mathrm{K}$ the $\Delta\left(\mathrm{G}^{1 / 2}\right)$ and instead of $\mathrm{K}_{\max }$ and $\mathrm{K}_{\min }$ the $\left(\mathrm{G}_{\max }\right)^{1 / 2}$ and $\left(\mathrm{G}_{\min }\right)^{1 / 2}$, respectively.

Therefore, it is possible to write the $K_{\text {th }}$ as:

$K_{t h}=\left(E G_{t h} / 1-\alpha v^{2}\right)^{1 / 2}$

and to rewrite the $\mathrm{G}_{\mathrm{th}}$ as:

$G_{t h}=K_{t h}^{2}\left(1-\alpha v^{2}\right){ }_{E}$

since $\alpha$ is a measure of stress triaxiality degree, that may vary between 0 and 1 ( $\alpha=0$ for plane stress and $\alpha=1$ for plane strain condition), and $v$ is the Poisson ratio. The same is true for the $\mathrm{K}_{\max , \mathrm{th}}$ and, therefore, it can be rewritten as: 


$$
G_{m a x, t h}=K_{\max , t h}^{2}\left(1-\alpha v^{2}\right) / E
$$

then, $\Delta \sqrt{G_{t h}}=\sqrt{\Delta K_{t h}^{2}\left(1-\alpha v^{2}\right) / E}$

Finally, the stress ratio R as:

$R=G_{\min }^{1 / 2} / G_{G_{\max }^{1 / 2}}^{1 / 2}$ and, the Vasudevan law can be rewrite as:

$d a / d N=A\left(\Delta \sqrt{\overline{G_{e q}}}-\Delta \sqrt{\overline{G_{t h}}}\right)^{n}\left(\sqrt{\overline{G_{\text {max }, e q}}}-G_{\text {max }, t h}\right)^{m}$

The rewriting and use of Vasudevan's law in energy terms is very important when elastic-plastic material properties are used and if the growth of the plastic zone ahead the crack front prevents the Stress Intensity Factors to describe correctly the crack front conditions.

\section{Results and Discussion}

In fig. 4, the residual stresses field produced at the end of thermo-mechanical simulation is shown for the FSW joint at the releasing step (Step5).

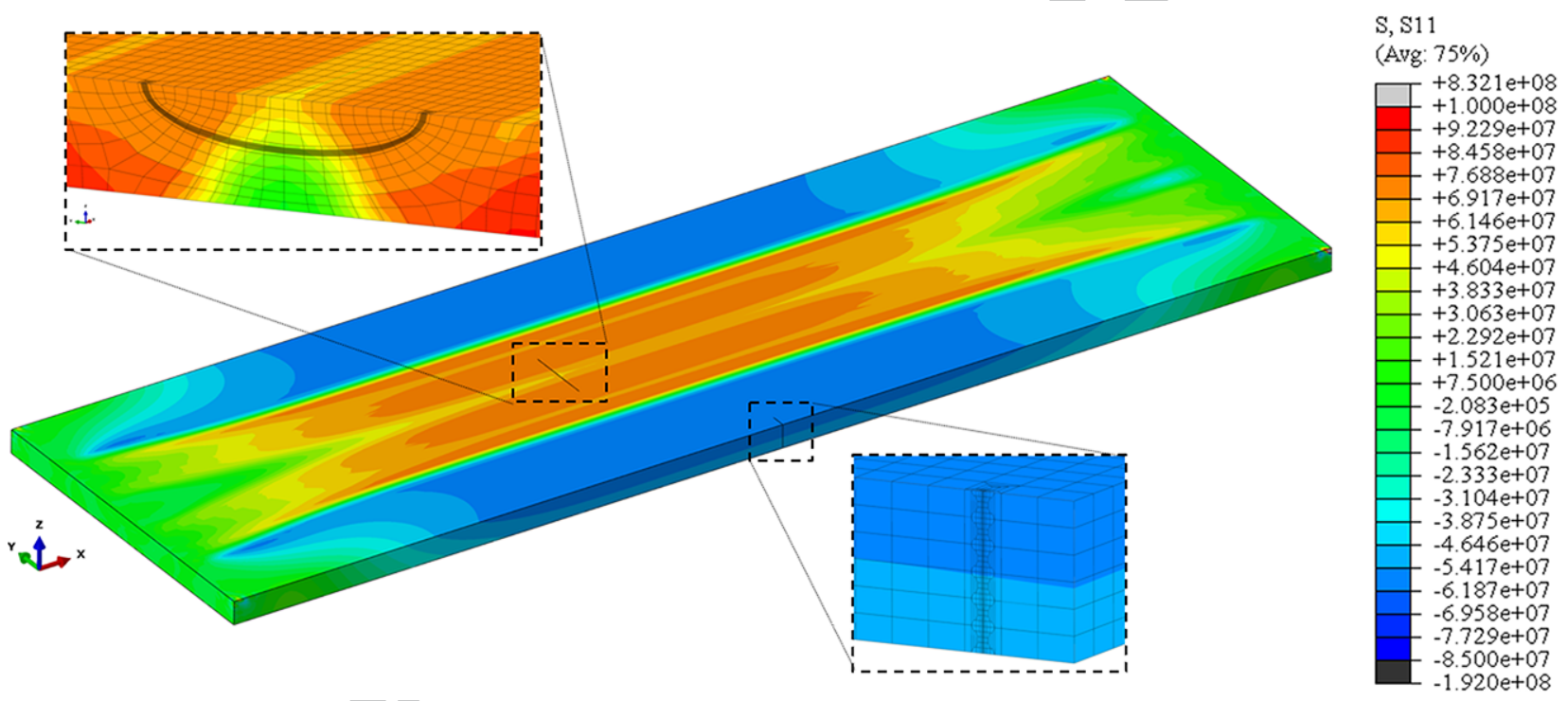

Fig. 4. The element nodes located on the crack faces have the same stress and displacement values $\left(\mathrm{Pa}^{\wedge} \mathrm{m}^{\wedge 0.5}\right)$.

Following the cooling of the joint, a metal contraction occurs along the direction of the welding path (longitudinal). This contraction is conteracted by surrounding base metal. This action of contrast lead to the formation of residual tensile stresses (weld bead) and residual compression stresses (externally to the weld bead material) in the welded joint domain. Equilibrium is achieved by combining these stresses in the areas immediately surrounding the weld bead. This peculiarity of the welding process can be clearly distinguished from the observation of the residual stress distribution shown in fig. 5 where the residual stress profiles are evaluated in the midline of the thickness, at the end of the releasing step and for the virtual uncracked configuration. In particular, the solution adopted in this case is obtained from a model where only linear elements (C3D8) are used whilst the solution adopted in the FEM-DBEM approach is obtained from a FEM model where only quadratic elements (C3D20) are used. Looking at profiles shown in fig. 5, it is clearly visible that some differencies occurs compairing those profiles. The biggest differences are highlighted in the central part of the model where the central crack is located. However, this gap can be reduced by increasing the mesh density in correspondence of the central crack. 


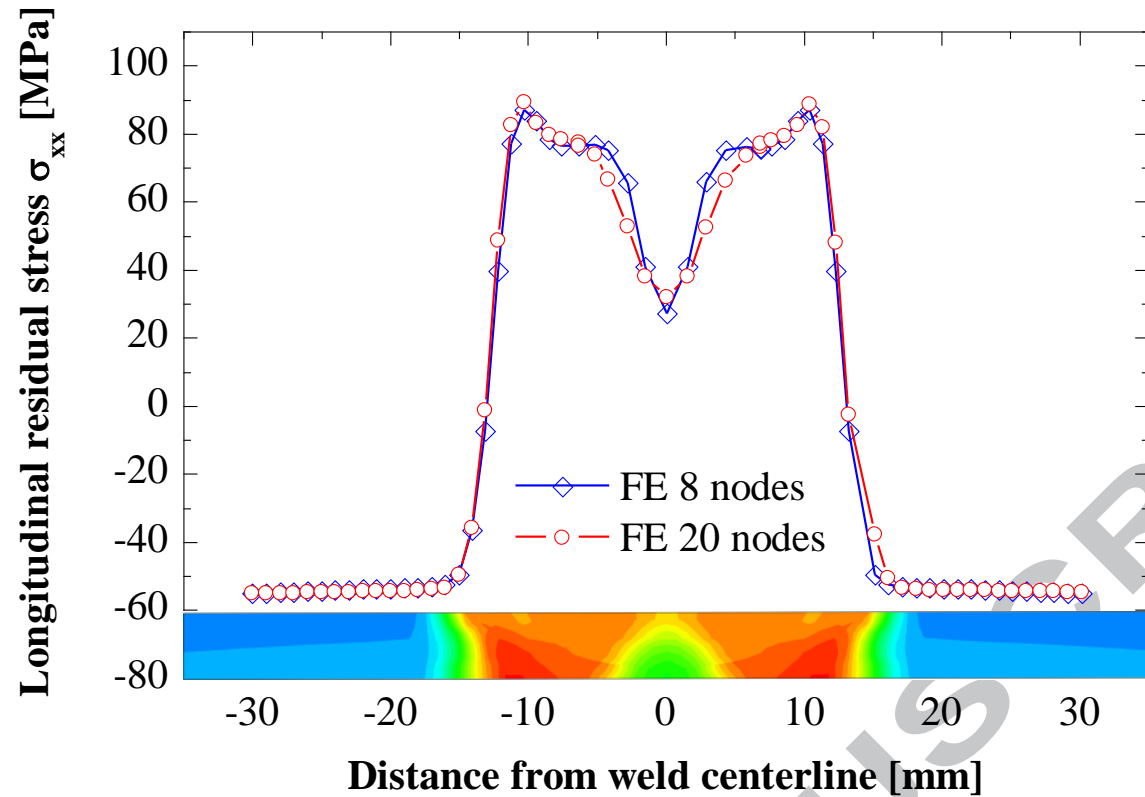

Fig. 5. Residual stress profiles evaluated on the section containing the central crack. The $\sigma_{x x}$ contour plot is relative to the eight and twenty nodes FEM solutions.

Initially, in the un-cracked FE model, the only lateral crack is introduced and the SIFs trend along the crack front, produced by the combination of residual stresses and those generated by the remote load (100 MPa), are estimated for the only phase of the crack insertion. These SIFs are compared with those produced at the end of an analogous DBEM-based analysis (Fig.6). Regarding the FEM-based analysis, among the various collapsed block families available in the library, it was chosen to use the one belonging to the $\mathrm{S} 03$ family, which introduces a maximum of three ring elements for the mapping and three contours for the J-integral calculation. The KI evaluation study, carried out along the front of the only lateral crack, takes place considering the residual stress scenario previously calculated. The plastic radius dimension, evaluated along the crack front, is such that it remains within the Linear Elastic Fracture Mechanics (LEFM).

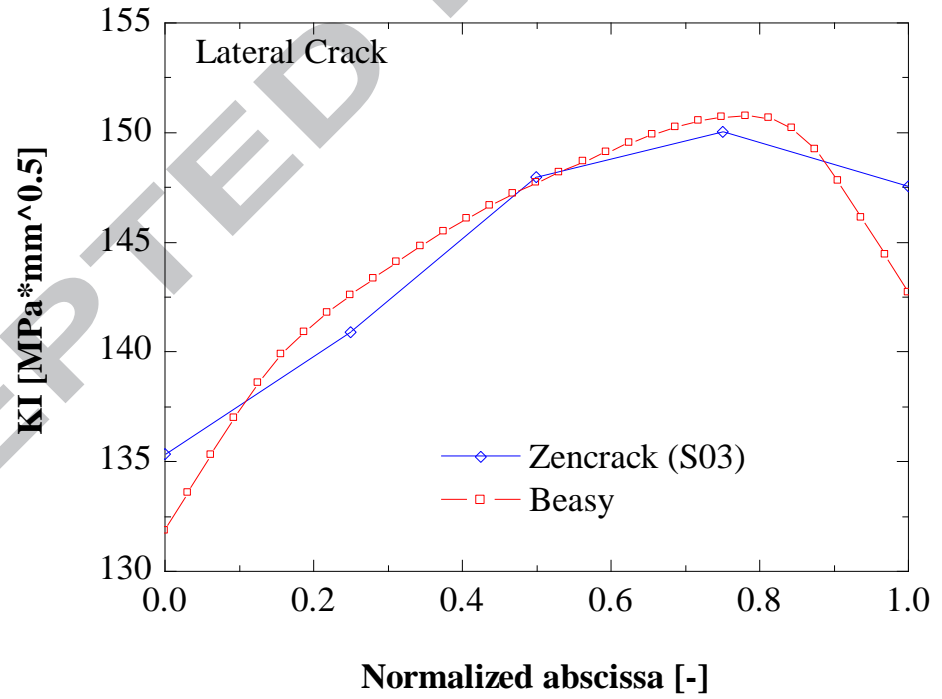

Fig. 6. KI comparison evaluated along the lateral crack front for the FEM and FEM-DBEM analyses, respectively.

The total stress calculation is made up of two steps. In the first step (step0), the only constraints applied on the crack faces are removed (the crack can open), while in the second (step1) also applies the remote load. At the end of the first step, the initial residual stresses relative to the un-cracked model (thermo-mechanical analysis) are redistributed throughout the domain. This effect is clearly visible near the cracks (Fig. 7). 


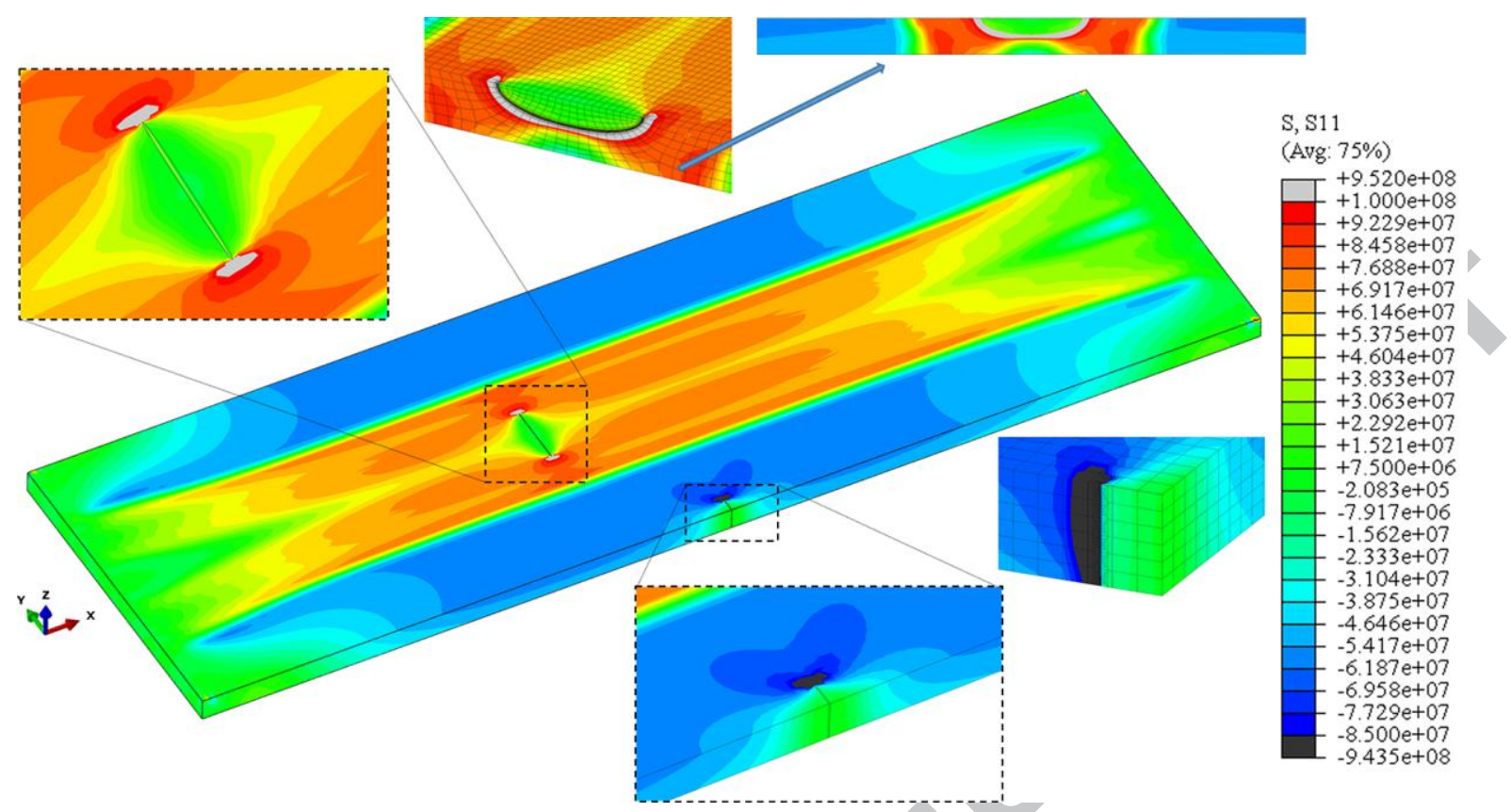

Fig. 7. Residual stress scenario and highlight of their redistributions near the cracks at the end of the step0 $\left(\mathrm{Pa}^{*} \mathrm{~m}^{\wedge 0.5}\right)$.

In figure 8 , the residual stresses profile, redistributed at the end of the step0, is shown. The effect of this redistribution is clearly visible around the area affected by the welding process where residual stresses are opening and in correspondence of the central crack.

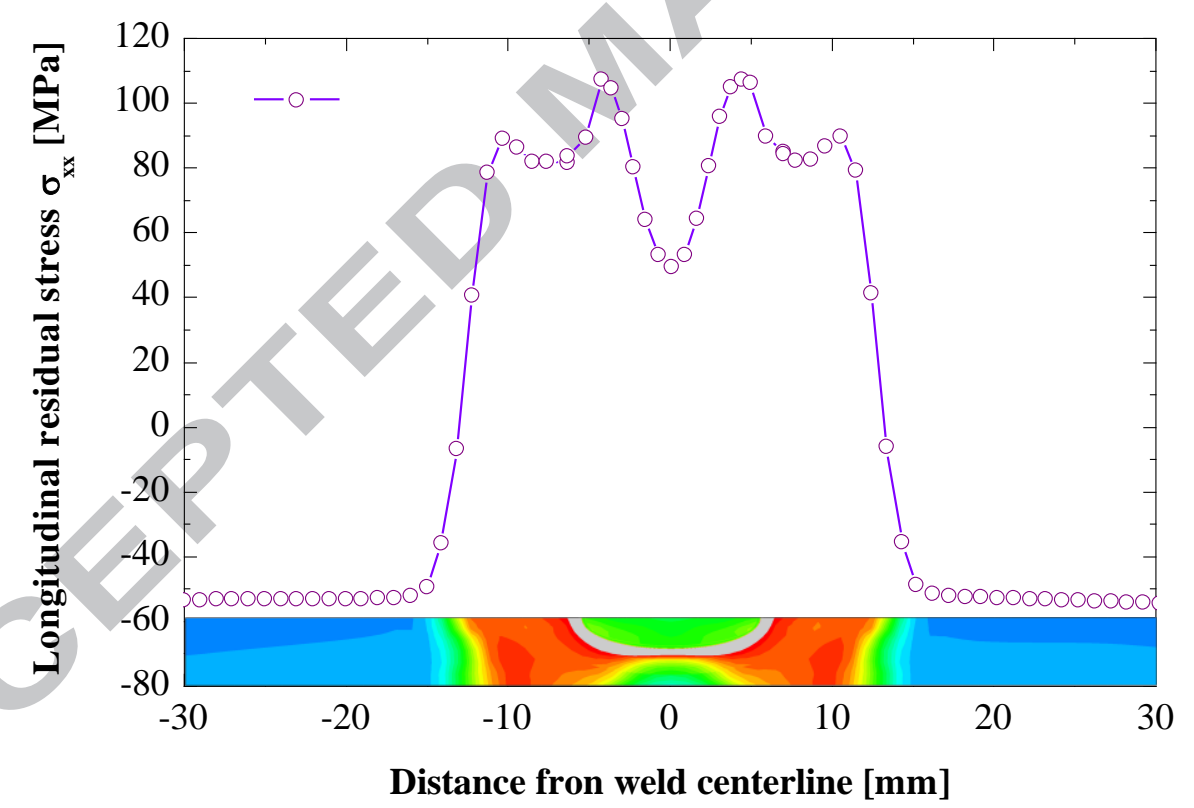

Fig. 8. Redistributed residual stresses profile after removal contact constraints applied on the cracks faces (step0) and evaluated on the section containing the central crack.

The remote load (step1) applies after the step of removing constraints imposed on the crack faces at step0. In figure 9, the overall stresses distribution in the load direction is shown with some details of such stresses in the regions affected by the cracks. The total stress is obtained by superposition of residual stresses and those produced by the nominal load. 


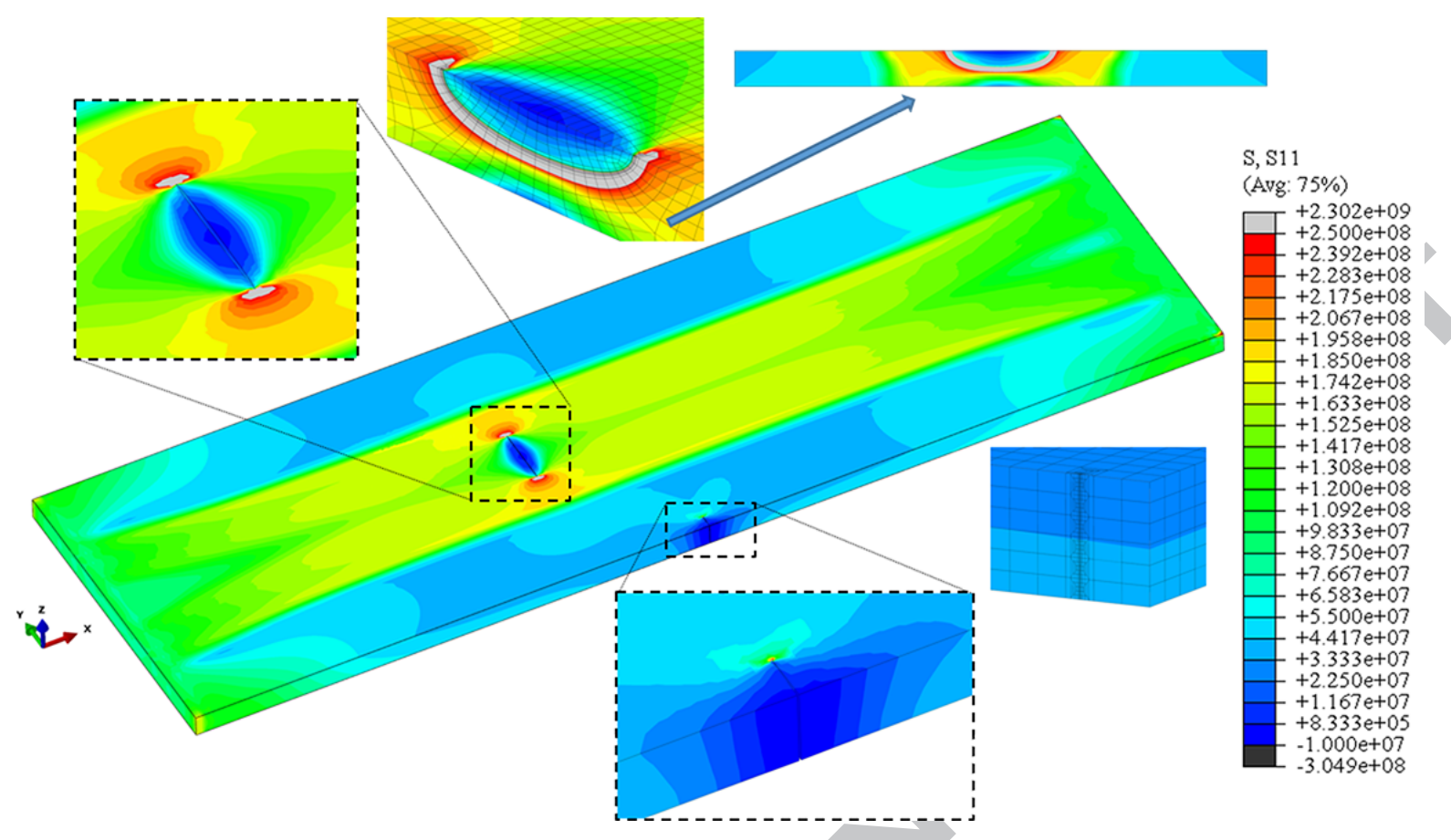

Fig. 9. Stress distribution $\left(\mathrm{Pa}^{*} \mathrm{~m}^{\wedge 0.5}\right)$ at the end of remote load application with highlight of the cracked regions.

Figure 10 shows the overall stresses evaluated along the thickness of the welded joint in the direction of the applied load.

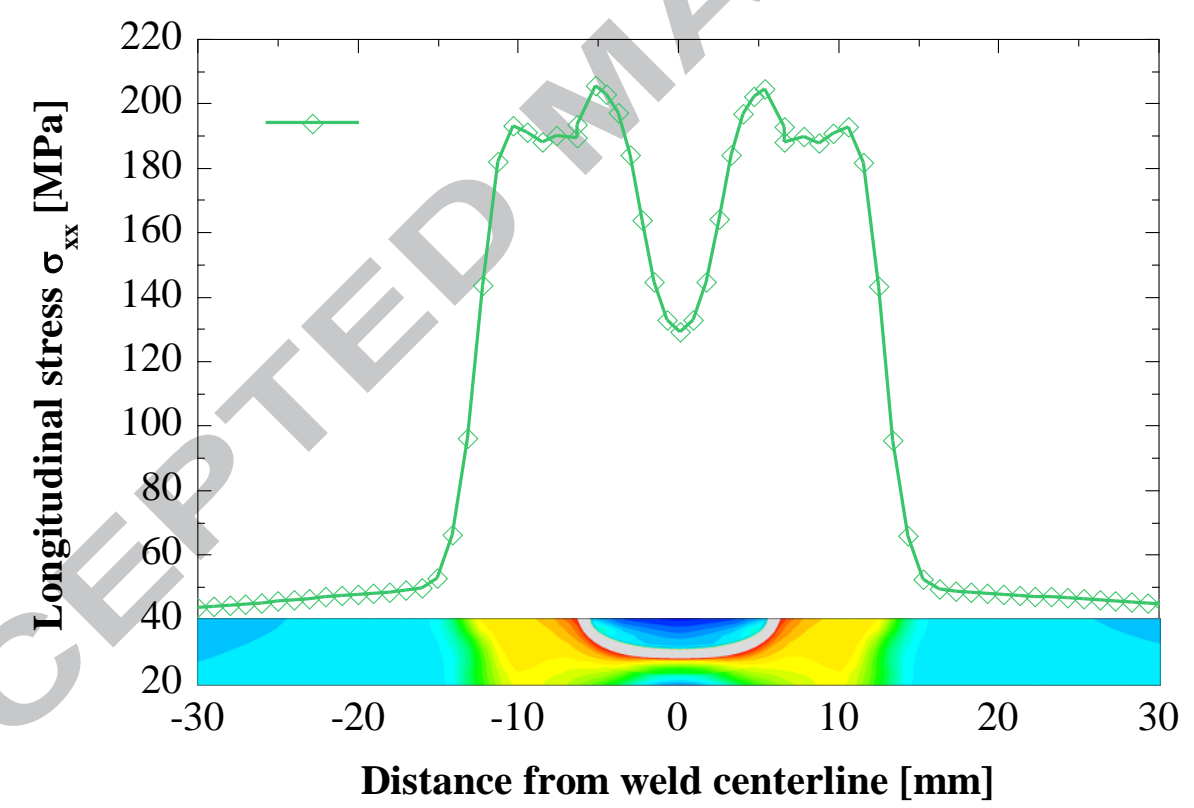

Fig. 10. Domain stress distribution (step1) at the end of the load application and evaluated on the section containing the central crack.

Residual stresses, calculated with a FEM analysis in the whole domain of the un-cracked model, are imported, transformed and applied only on the crack faces in an analogous DBEM model. In fig. 11, stresses in the load direction (along the X axis) are shown and evaluated for the DBEM cracked model. The adopted mesh is made up of 2084 quadratic elements (Q3) with 29823 nodes. The advantages offered by the use of this numeric method are sundry. Indeed, it is not only easier to discretion of the domain, working exclusively on the boundary, but it is also possible to introduce the cracks in the un-cracked model by inserting them directly from a library where they are stored in a parametric form. In this case, the residual stresses previously calculated in the thermo-mechanical model with finite elements are imported only on the crack faces (Bueckner approach) [34]. The linear elasticity hypothesis allows to apply the superposition principle for the SIFs calculation, namely, to add to the imported residual stresses those one produced by the remote load. In particular, the Bueckner approach states that the effect produced on SIFs by residual stresses not only can it be modeled with a distribution of tractions directly applied on the crack faces, but also that such effect continues to be true even during the fatigue propagation phase and that for each crack growth step. 


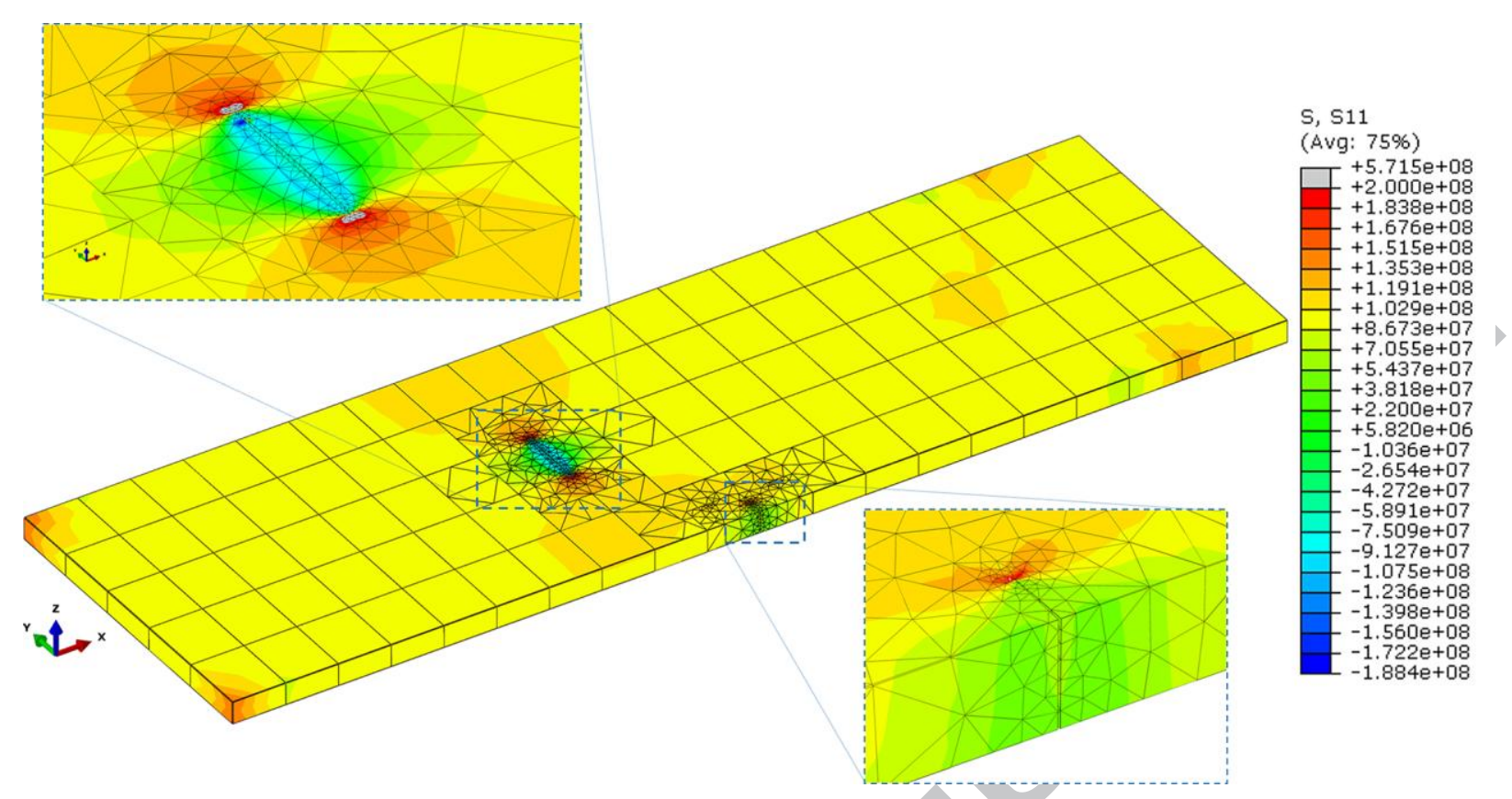

Fig. 11. Stress distribution $\left(\mathrm{Pa}^{*} \mathrm{~m}^{\wedge 0.5}\right)$ at the end of remote load application with highlight of the cracked zones (FEM-DBEM).

In figs. 12a, 12b, the overlapping of the SIFs, calculated with J-Integral and for the two cracks is shown. These results coming from FEM and FEMDBEM analyses, respectively. The residual stresses are applied in the DBEM environment not throughout the domain but only on the crack faces. Furthermore, such stresses are applied as tractions on the nodes of each element placed on the crack faces. It is important to observe that, in this case, the FEM solution used to import the residual stress field is obtained by an analysis in which elements are quadratic with full integration (C3D20).

A FEM calculation carried out with volume elements, whose interpolation order is quadratic, allows in the DBEM to add a more accurate residual stress profile to the crack faces. Of course, cracks discretion would be sufficiently fine to be able to perceive such accuracy.
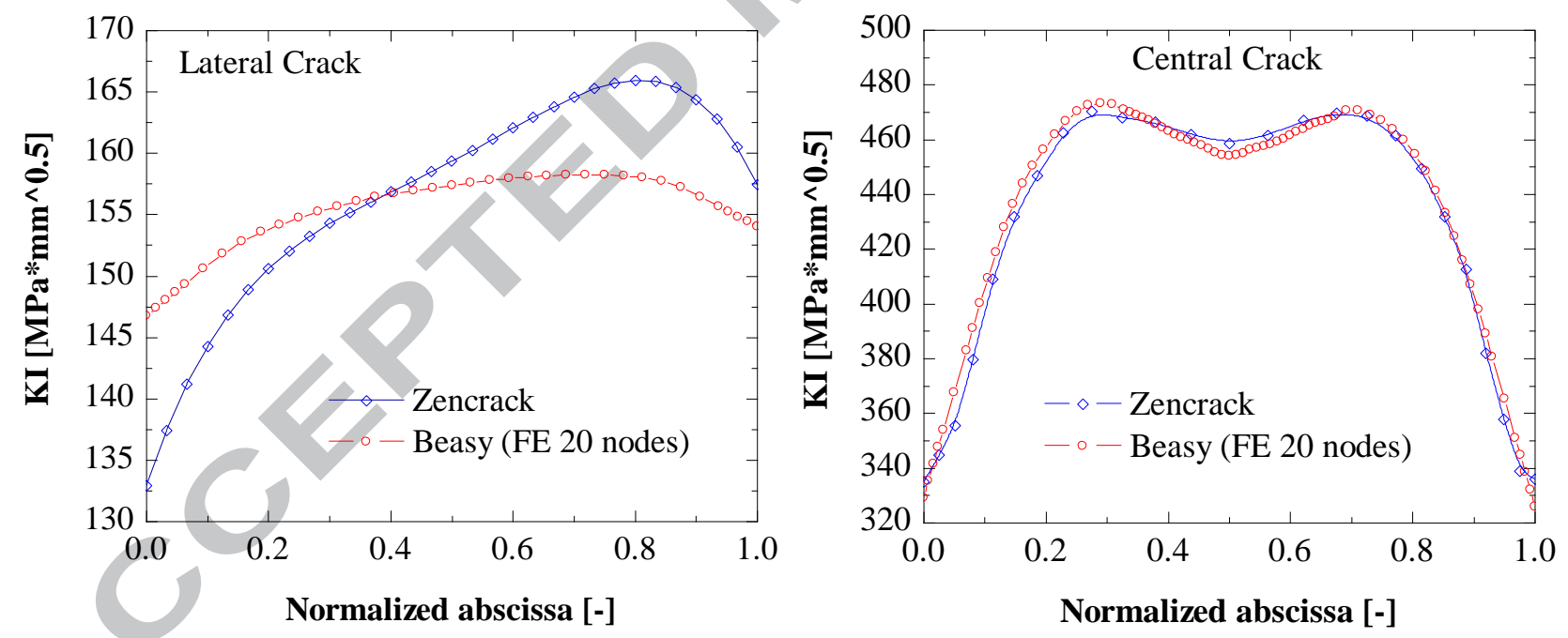

Fig. 12a, 12b. KI profiles evaluated along the lateral and central crack fronts, respectively, at the insertion phase.

In figs. 13a, 13b, the KI evaluated along the lateral and central crack fronts and produced by only residual stresses at the end of the cracks opening (step0) are shown. 

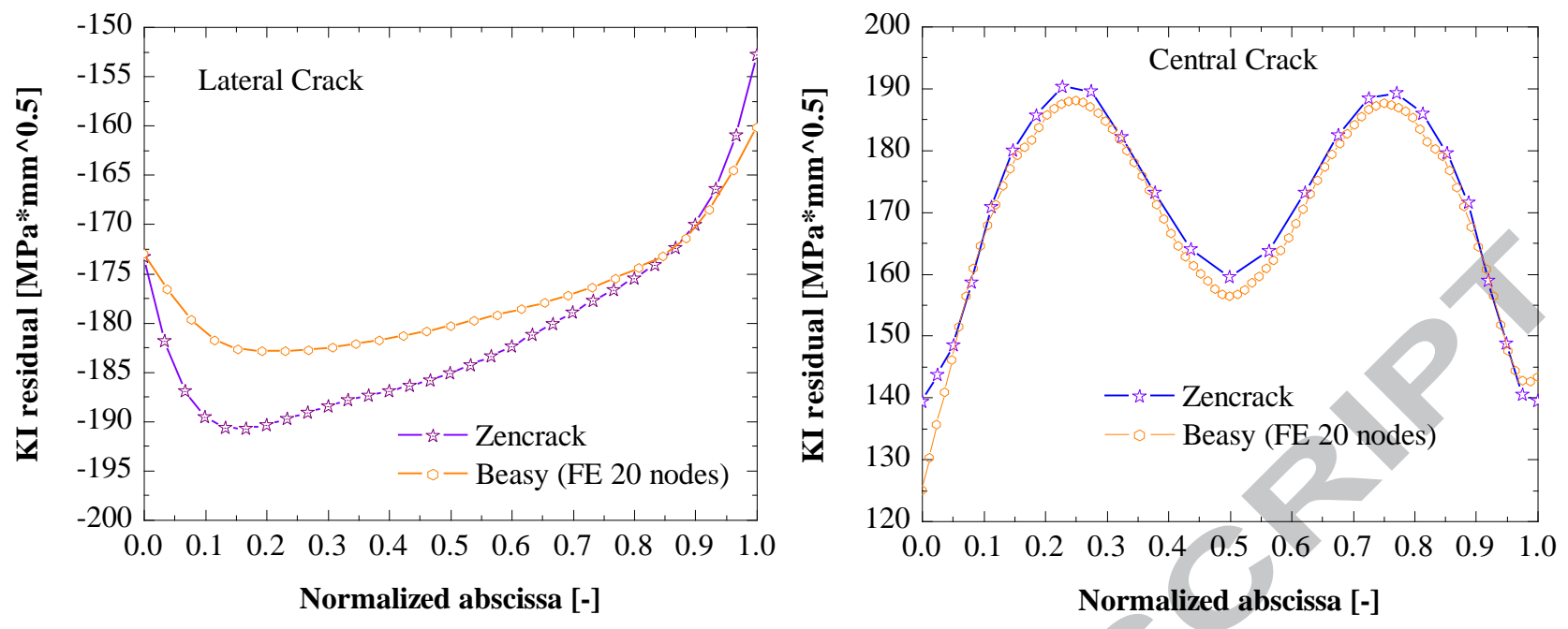

Fig. 13a, 13b. KI profiles evaluated along the lateral and central crack fronts, respectively, at the insertion phase and obtained considering only residual stresses.

For the lateral crack shown in fig. 13a, the difference in KI residual values (within 4\%) depends by the adopted mesh in the finite elements analysis. As stated before, for the FEM approach linear elements are used whilst quadratic elements are employed to calculate the residual stresses to be transferred later in DBEM environment (where quadratic elements are used to model the mesh and the cracks). When the tensile load is applied then differences between the total KI increase (fig.12a).

For both analyses FEM and FEM-DBEM, respectively, the cracks propagation develops in 41 computational steps with a maximum advance of three tenths of a millimeter. In fig. 14, the propagation data for the lateral crack only are shown. The maximum differences, measurable at the end of the propagation between the measurement points A and B, and FEM, FEM-DBEM analyses, are within a range of about a tenth of a millimeter and are equal to $4 \%$, highlighting a good agreement. Similarly for the point $\mathrm{C}$, cracks measurements at the end of the propagation show that maximum difference is within the limit of $3 \%$.

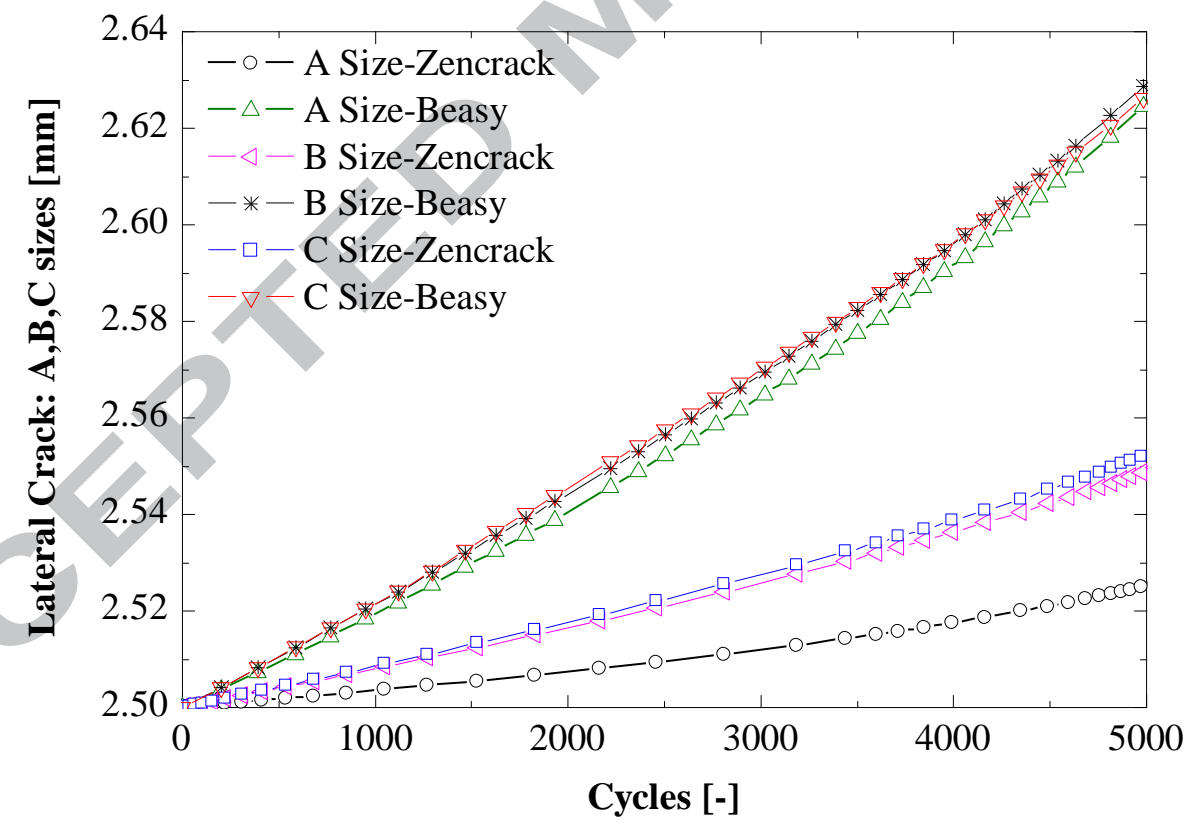

Fig. 14. Overlap of the a-N trends for the three measurement points during the propagation of the lateral crack only.

In fig. 15, the propagation data for the only central crack are shown. The maximum difference, measured between the measuring points A and B at the end of the propagation and for the FEM and FEM-DBEM analyses is within a range of 0.5 millimeters and equal to 6\%. For the calculated measurements of points $\mathrm{C}$ this difference is within $4 \%$ showing a good agreement also in this case. 


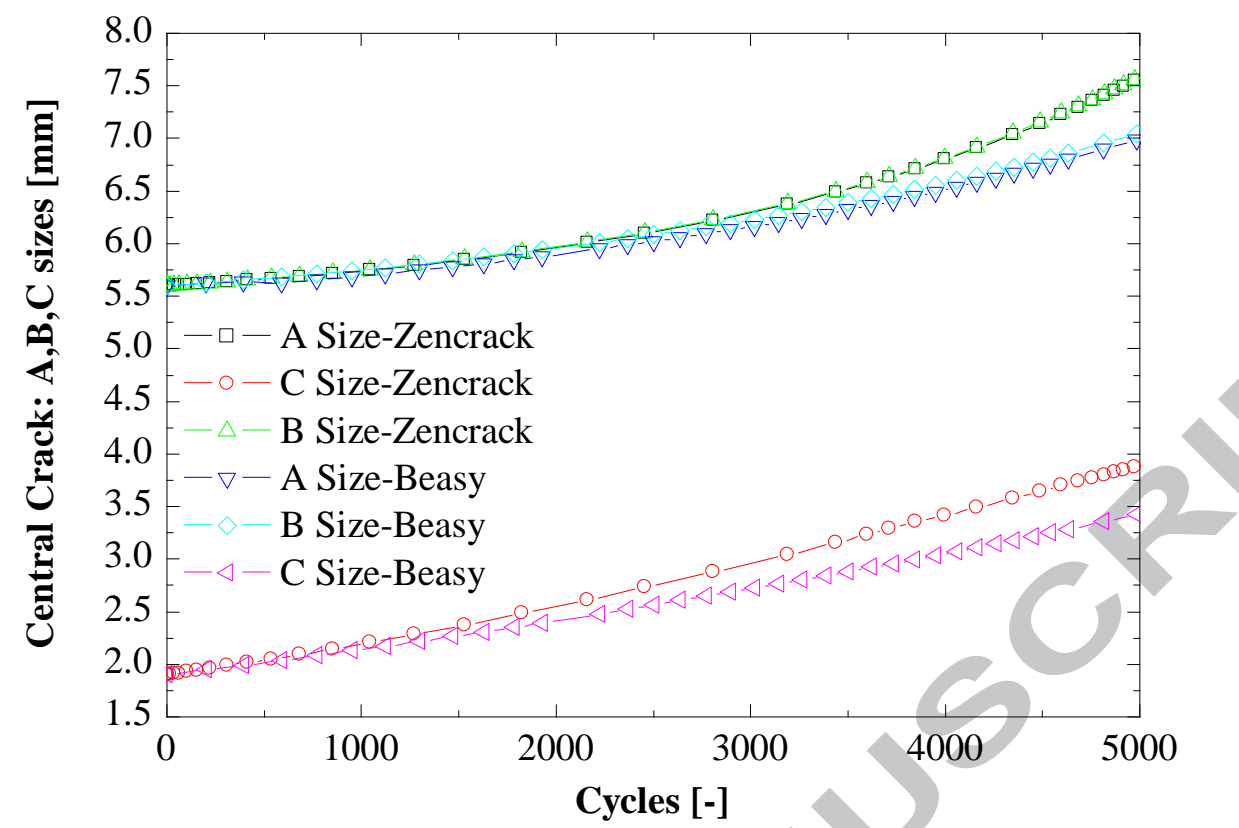

Fig. 15. Overlap of the a-N trends for the three measurement points during the propagation of the central crack only.

The data shown in figs. 14-15, highlight a satisfactory agreement of numerical results produced by FEM and FEM-DBEM analyses and allow to validate the proposed procedure in this work.

\section{CONCLUSIONS}

In this work, the fatigue propagation of multiple three-dimensional cracks in a welded component are simulated by both FEM and FEM-DBEM approaches. Taking into account the discussed results, the following conclusions can be highlighted:

The simulations of the un-cracked model and the cracked one, where contact conditions are applied on the crack faces, lead to the same residual stress field, as can be seen from the comparison of the initial residual stress profiles.

in the FEM model, the relaxation of the contact conditions applied on the crack faces allows the residual stresses to redistribute leading to a new internal, as in the DBEM model;

$\checkmark$ both models account for residual stress effect on crack growth rate;

$\checkmark$ the proposed FEM approach does not require any importation of residual stress distribution, differently from the FEM-DBEM model;

$\checkmark$ the proposed procedure introduce the capability for SIFs calculation in a cracked model with elastic-plastic material properties and with an initial residual stress scenario, by introducing an elastic-plastic tip;

$\checkmark \quad$ a satisfactory agreement between the FEM and FEM-DBEM simulations was found with respect to the cracks evolution for each propagation step;

$\checkmark$ the use of linear elements to calculate the residual stress field and the cracks propagation by FEM simulation allow to reduce the computational times. 


\section{REFERENCES}

[1] N. Sukumar, D.L. Chopp, B. Moran. Extended Finite Element Method and Fast Marchin Method. Eng Fract Mech., 70 (2003) 29-48.

[2] M. da Fonte, L. Reis, M. de Freitas. Fatigue crack growth under rotating bending loading on aluminum alloy $7075-T 6$ and the effect of a steady state torsion. Theoretical and Applied Fracture Mechanics, Vol. 80, Part A, 2015, Pages 57-64.

[3] U. Zerbst, R.A. Ainsworth, et al. Review on fracture and crack propagation in weldments - A fracture mechanics perspective. Eng Fract Mech., 132 (2014), 200-276.

[4] P. Dong, J. Zhang. Residual stresses in strength-mismatched welds and implications on fracture behavior. Eng Fract Mech., 64 (1999), 485-505.

[5] Darko M. VELJIC et al. A coupled thermo-mechanical model of friction stir welding. THERMAL SCIENCE, 2012, Vol. 16, No. 2, pp. 527-534.

[6] R. Citarella., G. Cricrì. A two parameter model for crack growth simulation by combined FEM-DBEM approach. Advances in Engineering Software, Volume 40, Issue 5, May 2009, Pages 363-377.

[7] Z ivojinovic' D, Đurdevic' A, Grbovic' A, Sedmak A, Rakin M. Numerical modelling of crack propagation in friction stir welded joint made of aluminium alloy. Proc Mater Sci 2014;3:1330-5.

[8] Zadeh M, Ali A, Golestaneh AF, Sahari BB. Three dimensional simulation of fatigue crack growth in friction stir welded joints of 2024-t351 Al alloy. J Sci Ind Res 2009;68:775-82.

[9] Citarella R, Carlone P, Lepore M, Palazzo GS. Numerical-experimental crack growth analysis in AA2024-T3 FSWed butt joints. Adv Eng Softw 2015;80:47-57.

[10] Citarella R, Carlone P, Sepe R, Lepore M. Hybrid technique to assess the fatigue performance of multiple cracked FSW joints. Eng Fract Mech.

[11] Sonne MR, Carlone P, Palazzo GS, Hattel JH. Numerical modeling of AA2024-T3 friction stir welding process for residual stress evaluation, including softening effects. Key Eng Mater 2014;611-612:1675-82.

[12] Carlone P, Palazzo G. Influence of process parameters on microstructure and mechanical properties in AA2024-T3 friction stir welding. Metall Microstruct Anal 2013;2:213-22.

[13] Paulo, R.M.F., Carlone, P., Valente, R.A.F., Teixeira-Dias, F., Palazzo, G.S. Influence of friction stir welding residual stresses on the compressive strength of aluminum alloy plates, Thin-Walled Structures 74, pp. 184-190

[14] Dialami N, Chiumenti M, Cervera M, de Saracibar C Agelet. Challenges in thermo-mechanical analysis of friction stir welding processes. Arch Comput Method E. http://dx.doi.org/10.1007/s11831-015-9163-y.

[15] D.N. dell'Erba, M.H. Aliabadi. On the solution of three-dimensional thermoelastic mixed-mode edge crack problem by the DBEM. Eng Fract Mech., 66 (2000), 269-285.

[16] Xiangqiao Yan. Automated simulation of fatigue crack propagation for two-dimensional linear elastic fracture mechanics problems by boundary element method. Eng Fract Mech., 74 (2007), 2225-2246.

[17] R. Citarella, G. Cricrì. Comparison of DBEM and FEM crack path predictions in a notched shaft under torsion. Eng Fract Mech., 77 (2010), $1730-1749$

[18] Citarella R, Carlone P, Sepe R, Lepore M. DBEM crack propagation in friction stir welded aluminum joints. Adv Eng Softw.

[19] Carlone P, Citarella R, Lepore M, Palazzo GS. A FEM-DBEM investigation of the influence of process parameters on crack growth in aluminum friction stir welded butt joints. Int J Mater Form 2015;8(4):591-9.

[20] Chao YJ, Qi XH (1998) Thermal and thermo-mechanical modeling of friction stir welding of aluminum alloy 6061-T6. J Mater Process Manuf Sci 7(2):215-233.

[21] Zhu XK, Chao (2004) Numerical simulation of transient temperature and residual stresses in friction stir welding of 304 L stainless steel. J Mater Process Technol 146:263-272.

[22] Chen CM, Kovacevic R (2006) Parametric finite element analysis of stress evolution during friction stir welding. Proceedings of the Institution of Mechanical Engineers Part B: J Eng Manuf 220(8):1359-1371.

[23] Li T, Shi QY, Li HK (2007) Residual stresses simulation for friction stir welded joint. Sci Technol Weld Join 12(8):634-640

[24] Hattel JH, Sonne MR, Tutum CC. Modelling residual stresses in friction stir welding of Al alloys - a review of possibilities and future trends. Int J Adv Manuf Technol 2015;76(9):1793-805.

[25] Xiaocong He. Fengshou Gu. A review of numerical analysis of friction stir welding, Progress in Materials Science. Volume 65, August 2014, Pages 1-66.

[26] He X, Gu F, Ball A. A review of numerical analysis of friction stir welding. Prog Mater Sci 2014;65:1-66.

[27] Schmidt H, Hattel JH. Thermal modelling of friction stir welding. Scripta Mater 2008;58:332-7.

[28] Sonne MR, Tutum CC, Hattel JH, Simar A, de Meester B. The effect of hardening laws and thermal softening on modeling residual stresses in FSW of aluminum alloy 2024-T3. J Mater Process Technol 2013;213:477-86.

[29] Richards DG, Pragnell PB, Williams SW, Withers PJ. Global mechanical tensioning for the management of residual stresses in welds. Mater Sci Eng A 2008;489:351-62.

[30] Carlone P, Citarella R, Sonne MR, Hattel JH, Multiple crack growth prediction in AA2024-T3 friction stir welded joints, including manufacturing effects, International Journal of Fatigue 90 (2016) 69-77

[31] Sonne MR, Carlone P, Palazzo GS, Hattel JH. Numerical modeling of AA2024-T3 friction stir welding process for residual stress evaluation, including softening effects. Key Eng Mater 2014;611-612:1675-82.

[32] Myhr OR, Grong O. Process modeling applied to 6082-T6 aluminum weldments. Part 1: Reaction kinetics. Part 2: Applications of model. Acta Metall 1991;39:2693-708.

[33] Zencrack documentation. Zentech International Limited, 2017.

[34] Buekner HF. The propagation of cracks and the energy of elastic deformations. TRANS ASME 1958;80:1225-30 


\section{Highlights}

- A FEM based methodology for the simulation of multiple crack propagation is presented.

- Residual stresses are calculated starting from a cracked but virtually continuous component.

- The procedure was validated by comparison with a FEM-DBEM approach. 